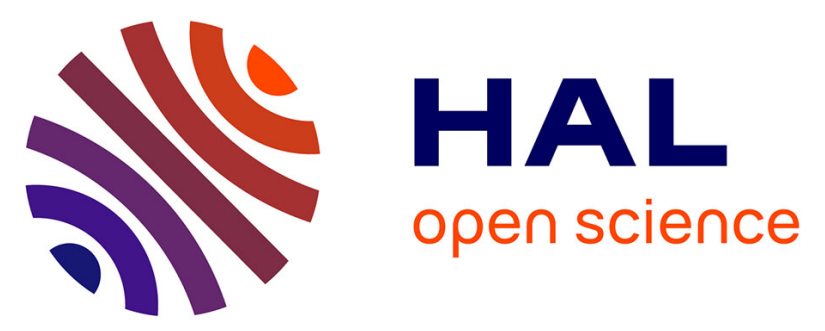

\title{
Towards a non-invasive quantitative analysis of the organic components in museum objects varnishes by vibrational spectroscopies: Methodological approach
}

Céline Daher, Vanessa Pimenta, Ludovic Bellot-Gurlet

\section{To cite this version:}

Céline Daher, Vanessa Pimenta, Ludovic Bellot-Gurlet. Towards a non-invasive quantitative analysis of the organic components in museum objects varnishes by vibrational spectroscopies: Methodological approach. Talanta, 2014, 129, pp.336 - 345. 10.1016/j.talanta.2014.05.059 . hal-01455436

\author{
HAL Id: hal-01455436 \\ https://hal.science/hal-01455436
}

Submitted on 3 Feb 2017

HAL is a multi-disciplinary open access archive for the deposit and dissemination of scientific research documents, whether they are published or not. The documents may come from teaching and research institutions in France or abroad, or from public or private research centers.
L'archive ouverte pluridisciplinaire $\mathbf{H A L}$, est destinée au dépôt et à la diffusion de documents scientifiques de niveau recherche, publiés ou non, émanant des établissements d'enseignement et de recherche français ou étrangers, des laboratoires publics ou privés. 


\title{
Towards a non-invasive quantitative analysis of the organic components in museum objects varnishes by vibrational spectroscopies: Methodological approach
}

\author{
Céline Daher*, Vanessa Pimenta, Ludovic Bellot-Gurlet \\ Sorbonne Universités, UPMC Université Paris 6, MONARIS “de la Molécule aux Nano-objets: Réactivité, Interactions et Spectroscopies”, UMR 8233, \\ UPMC-CNRS, Paris, France
}

\section{A R T I C L E I N F O}

\section{Article history:}

Received 28 January 2014

Received in revised form

23 May 2014

Accepted 30 May 2014

Available online 10 June 2014

\section{Keywords:}

FT-Raman

IR-reflectance

Non-invasive quantification

Spectral decomposition

Varnish

Museum objects

\begin{abstract}
A B S T R A C T
The compositions of ancient varnishes are mainly determined destructively by separation methods coupled to mass spectrometry. In this study, a methodology for non-invasive quantitative analyses of varnishes by vibrational spectroscopies is proposed. For that, experimental simplified varnishes of colophony and linseed oil were prepared according to 18th century traditional recipes with an increasing mass concentration ratio of colophony/linseed oil. FT-Raman and IR analyses using ATR and non-invasive reflectance modes were done on the "pure" materials and on the different mixtures. Then, a new approach involving spectral decomposition calculation was developed considering the mixture spectra as a linear combination of the pure materials ones, and giving a relative amount of each component. Specific spectral regions were treated and the obtained results show a good accuracy between the prepared and calculated amounts of the two compounds. We were thus able to detect and quantify from $10 \%$ to $50 \%$ of colophony in linseed oil using non-invasive techniques that can also be conducted in situ with portable instruments when it comes to museum varnished objects and artifacts.
\end{abstract}

(c) 2014 Elsevier B.V. All rights reserved.

\section{Introduction}

The works of art varnishes have miscellaneous roles. It protects the work of art (painting, music instrument, or furniture) against the aggression of various environmental factors such as dust, air pollutants or light and to resist over time; but it also has an important esthetic role to enhance or create visual effects. Indeed, this thin transparent layer has some optical properties that enhance contrast, saturate the colors, and give depth and a glossy effect to the painting or the wooden artifact.

Varnishes are made of resins dissolved in a solvent, mostly siccative oil, and for some historical periods or specific uses, alcohol or spirit. Sometimes, mineral siccative agents or pigments can be added to the varnish (especially for music instruments, or furniture) to give a slight and attenuated color to the object, while keeping the transparency and glossy effects. Depending on the desired finish of the surface, but also on the proper preparation viscosity for an optimal application, the craftsman or the artist adapts the proportions of each constituent. Defining a

\footnotetext{
* Corresponding author. Current address: Centre de Recherche sur la Conservation des Collections (CRCC) USR3224 CNRS-MCC-MNHN, Muséum National d'Histoire Naturelle, 36 rue Geoffroy Saint-Hilaire, CP 21, 75005 Paris, France. Tel.: + 33140795325 .

E-mail addresses: celine.daher@mnhn.fr, cel.daher@gmail.com (C. Daher).
}

methodology to detect and quantify different materials in a varnish is a way to enlighten ancient varnishing techniques, thus enhancing our knowledge in History of art and techniques.

Varnishes have been widely studied in order to get information about their compositions [1-5], the possible technologies used (heating, mixing), but also to identify their degradation and yellowing mechanisms by comparison with artificial ageing in order to characterize their original state [6-11], and even the quantification of their oxidation states [12-14]. Moreover, beside the alterations related to the chemical nature of the materials used, some studies are done on the possible biodegradation of varnishes due to some bacteria or fungi $[15,16]$. All these studies were mostly developed using separation methods coupled to mass spectrometry. Indeed, when working on varnishes, the presence, simultaneously, of different markers will give the varnish composition. However, these techniques are destructive and require an appropriate choice of analytical conditions and pre-treatments which are mostly time consuming.

Vibrational spectroscopies - Raman and infrared - are now being more and more developed following the performance enhancement of instrumentation. New horizons are now open, especially for the study of Cultural Heritage artifacts, thanks to the miniaturization of the devices and the development of portable instruments to get rid of the inflexible geometry of bench top spectrometers. These non-destructive and even non-invasive 
techniques do not require any sample preparation and allow onsite analysis directly on the artifacts whether for IR spectroscopy with different analytical modes such as diffuse and specular reflectance, or in the near-IR (NIR) range [17-19] or for Raman spectroscopy in the NIR [20-22]. Mathematical approaches are also being developed to get an improved exploitation of the obtained signatures and to establish new data treatment protocols easy to be applied to different issues. The spectra are no more studied in their raw form but are subjects to spectral derivatives [23], Principal Component Analyses [24-30] or spectral decomposition [31,32].

However, none of these techniques has yet been developed for quantitative purposes. One paper by Derrick [33], deals with some computer addition of pure material spectra in order to be compared to a varnish (mixture) spectrum. However, this work presents just one example, and the spectra comparison is mainly qualitative. The aim of this study is to develop a methodology to detect and quantify different components in a varnish by using FT-Raman spectroscopy and IR analyses in two analytical modes: ATR and specular reflectance, promoting non-destructive or even non-invasive analytical approaches. The very first idea to determine the presence of a compound in a mixture using its IR and Raman spectra would be to look for the presence of specific bands. However, varnishes are made of natural media that present the same chemical groups, and thus similar vibrational signatures. It becomes difficult to attest the presence of a compound in a mixture since its bands can be mixed up or hidden by another constituent of the varnish. It is therefore necessary to go deeper in the spectral interpretation and consider the profiles of the different constituents' spectra [26].

The materials used for this study were chosen depending on the most used materials for varnishing, especially for wooden objects such as music instruments or furniture since the 14th century and commonly employed during the 18th century. For example, previous studies about stringed instruments [3] using IR spectroscopy and separation methods (GC/MS) show the presence of a curing oil and a diterpenic resin (probably a pine resin). Moreover, this kind of objects is quite easy to analyze when working with non-invasive spectroscopies especially Raman and IR in reflectance mode. We chose thus to prepare mixtures of linseed oil and colophony. The multivariate approach here developed is based on the spectra of the materials present in the mixture whom linear combination must fit the mixture spectrum. For this purpose, experimental varnishes were prepared with increasing amounts of colophony in linseed oil, and the obtained results in terms of spectral adjustment and quantification, with each analytical approach, are discussed in this study. The novelty of this non-destructive and quantitative approach using portable IR in reflectance mode, and the analytical limits we faced mostly due to the materials natural alteration, are also taken in consideration. Finally, in order to monitor results from our vibrational methodology, some GC analyses, already approved for quantitative studies, were performed on the experimental varnishes.

\section{Materials and samples}

\subsection{Chemical composition}

The two employed materials have different chemistry. Indeed, colophony is a residue of the distillation of pine trees exudates and has as major diterpenic components abietic acid and its degradation products based on the abietane skeleton (Supplementary data S1): dehydroabietic acid (DHA), dehydro-dehydroabietic acid (dehydro-DHA), and 7-oxodehydroabietic acid (7-oxo-DHA) [34]. Linseed oil is made of triglycerides including 68\% of polyunsaturated fatty acids allowing an important polymerization of the oil films. The majors fatty acids (Supplementary data S1) contained in linseed oil are linoleic acid (C18:2), linolenic acid (C18:3), and oleic acid (C18:1) [35].

\subsection{Varnishes preparation}

It is known that varnishes can be prepared in different and very complex manners, with different heating times, and mainly the addition of various inorganic compounds as dryers for a better and faster curing of the varnish. For our study we aimed to quantify only the main components of varnishes to establish the general framework of a varnish recipe. We therefore focused on organics which will provide the main vibrational features of the varnish, avoiding minor inorganic compounds and their possible vibrational signatures.

In order to develop a quantification methodology using vibrational spectroscopy, a test set of varnishes with different mass concentrations of colophony/linseed oil was prepared and then applied to obtain different samples of varnish films.

Several preparations were so formulated: two are made only of the "pure" materials: colophony and linseed oil; then varnishes with an increasing mass concentration ratio of colophony/linseed oil were prepared, and the samples named with their respective content of colophony/linseed oil as the following: 05/95, 10/90, 20/ $80,30 / 70,40 / 60$ and 50/50 wt\%. The proportions were chosen in order to have relatively fluid varnishes easily applicable with a paintbrush (most common application form) on glass slides. One weak concentration (5\%) of colophony was chosen in order to have an evaluation of the limit of detection of this organic compound by Raman and Infrared spectroscopies. The preparation protocol was the following:

Crushing the resin.

Weighing the powder.

Dissolving the resin powder in ethanol.

Weighing the oil.

Homogenizing the mixture (stirring/warming at $90^{\circ} \mathrm{C}$, above ethanol boiling point).

Storing the varnish in a glass bottle.

And finally applying it on a glass support and leaving it for drying. The varnish films are with three layers thick $(\sim 100 \mu \mathrm{m})$, each layer being applied after the previous one got dry. All the varnishes were prepared at the same time, and let for drying with the same atmospheric conditions (air and daylight), and analyzed after 8 weeks of drying.

In the text, two representative conditions will be discussed in details the $05 / 95$ (5\% of colophony and $95 \%$ of linseed oil) and $40 /$ 60 (40\% of colophony and $60 \%$ of linseed oil) mixtures.

\section{Instrumentation}

\subsection{Raman spectroscopy}

To overcome fluorescence of the studied substances we performed FT-Raman analyses using a near infrared excitation at $1064 \mathrm{~nm}$ (Nd-YAG laser diode) associated with a Bruker RFS 100/S spectrometer built from a Michelson-type interferometer, and equipped with a liquid nitrogen-cooled Ge detector. The studied varnishes were analyzed using a macroscopic interface with a $90^{\circ}$ collection objective, allowing a spot size of $100 \mu \mathrm{m}$ approximately, and a power at the sample of $400 \mathrm{~mW}$ (maximum nominal power of $500 \mathrm{~mW}$ ). 
The varnishes were sampled and placed on a gold mirror to improve the collected Raman signal intensity; and no heating or damage of the films was observed. Spectra were recorded between 3500 and $50 \mathrm{~cm}^{-1}$ with a $4 \mathrm{~cm}^{-1}$ resolution and 1500 scans to optimize the analysis time and the signal-to-noise ratio. The flakes were analyzed many times in order to ensure the measurement reproducibility.

\subsection{Infrared spectroscopy}

\subsubsection{ATR mode}

Micro-infrared spectroscopy analyses in an Attenuated Total Reflectance (mono-ATR) mode were performed using a Bruker Equinox 55 spectrometer coupled to an IRscope II microscope equipped with a liquid nitrogen-cooled MCT detector. A $20 \times$ ATR objective equipped with a Germanium crystal (mono reflection) was used, allowing a $100 \mu \mathrm{m}$ spot size. It works whether in a visual mode for choosing the area to analyze, or in an IR mode for the measurement. The background was acquired by leaving the crystal in the air. To analyze the varnishes, this crystal needs to be in contact with the sample, and depending on the material hardness, it can lead to some damage. Since the experimental varnishes samples are rather soft, no damage was observed. 200 Scans were accumulated between 4000 and $600 \mathrm{~cm}^{-1}$ with a $4 \mathrm{~cm}^{-1}$ resolution. Different points were analyzed on all the flakes for reproducibility assessment.

\subsubsection{Reflectance mode}

Infrared analyses in a specular reflectance (SRefl) mode were performed using the Alpha portable spectrometer (Bruker) with the R-Alpha module. Within this module, the IR beam is focused via a set of mirrors with a $45^{\circ}$ incidence angle, resulting in a beam diameter of $5 \mathrm{~mm}$. The reflection is also collected with a $45^{\circ}$ angle - in order to minimize the diffuse reflectance - by another set of mirrors and taken to a DTGS detector. The background was acquired using a gold mirror as reference sample placed at the working distance is of $15 \mathrm{~mm}$, resulting in a total specular reflectance.

Since the varnish films are planar, smooth and shiny, they are perfectly suited to this measurement mode. They were analyzed by placing the glass blades in front of the measurement point (at the focal distance), and their spectra were collected between 4000 and $400 \mathrm{~cm}^{-1}$ at a resolution of $4 \mathrm{~cm}^{-1}$ and by accumulating 200 scans. All the samples were analyzed in several points to assess their homogeneity and the analytical reproducibility.

\subsection{Separation techniques}

\subsubsection{Sample pre-treatment}

The flakes taken from the varnish films were derivatized using $1 \mathrm{~mL}$ of $\mathrm{BF}_{3} \mathrm{MeOH}$ (Boron Trifluoride Methanol, 14\%) and placed during $48 \mathrm{~h}$ at $60 / 65^{\circ} \mathrm{C}$. The derivatization was then stopped by adding $2 \mathrm{~mL}$ of distilled water. The organic phase was extracted ( 4 times) using $1 \mathrm{~mL}$ of hexane. The solvent was evaporated under a flow of argon, and finally the extract was taken up in $100 \mu \mathrm{L}$ of hexane [36].

\subsection{2. $G C$}

A GC Trace (ThermoQuest) was used for the GC analyses with a splitless injector at $320^{\circ} \mathrm{C}$ and a FID detector at $320^{\circ} \mathrm{C}$. Chromatographic separation was carried out using a $30 \mathrm{~m}$ nonpolar column Zebron ZB-5 (Phenomenex) (0.25 mm inner diameter, and $0.25 \mu \mathrm{m}$ film thickness of $5 \%$ phenyl and 95\% dimethylpolysilane). The program used was a first programmed temperature ramp from 100 and up to $290{ }^{\circ} \mathrm{C}$ at $5{ }^{\circ} \mathrm{C} / \mathrm{min}$, then a second up to $320^{\circ} \mathrm{C}$ at $10{ }^{\circ} \mathrm{C} / \mathrm{min}$. The carrier gas (Ar) was used in a constant flow.
Each sample $(1 \mu \mathrm{L})$ was injected three times to assess the reproducibility of the measurement, and a blank injection was done before and after the analyses to control the absence of pollutants whether in the solvents used or the column.

\subsection{3. $G C / M S$}

The same program and GC characteristics were used for the GC analyses but using a Hewlett Packard HP5890 Serie II apparatus. A Hewlett Packard HP5989A mass spectrometer was used for the detection with a scan range from 45 to $600 \mathrm{~m} / z$, using electron ionization at $70 \mathrm{eV}$ and a quadrupole analyzer.

Only the pure materials films (100/0 and 0/100) were analyzed by GC/MS in order to select, on the TIC (with the help of their mass spectra) the peaks characteristic of each material for the quantitative analyses of the mixtures.

\section{Preliminary observations}

Fig. 1 presents the Raman and the IR (using an ATR and a Reflectance mode) spectra of the pure materials. The main bands
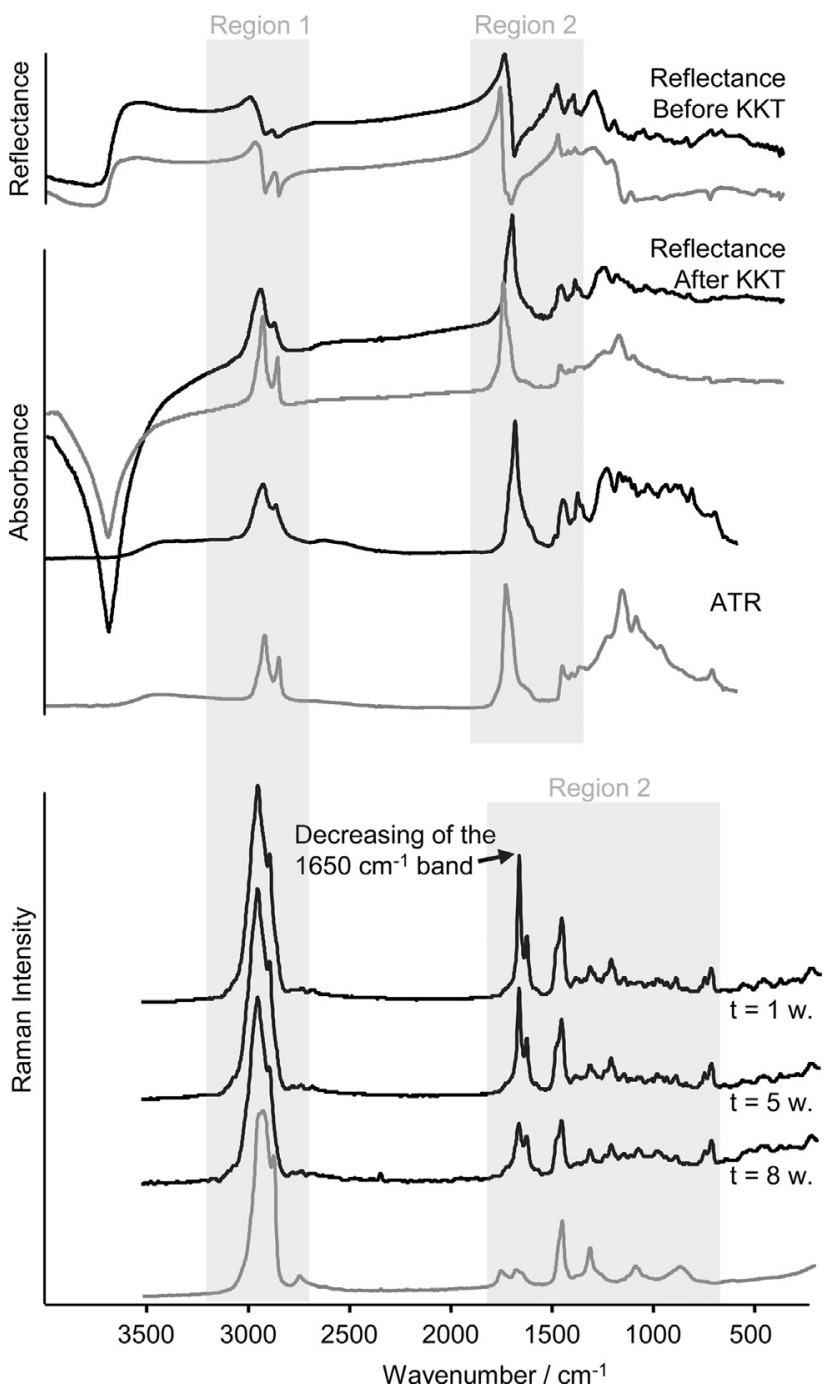

Fig. 1. Top: IR spectra of the studied materials, (black line: colophony, gray line: linseed oil) using different analysis modes. From top to bottom: Reflectance mode before then after the KKT correction, and ATR mode. The studied spectral regions (Regions 1 and 2) are also mentioned. Bottom: FT-Raman of the studied materials: linseed oil (gray line) and colophony (black line) with different drying times for the colophony film (1-8 weeks). The studied spectral regions (Region 1 and Region 2) are also mentioned. 
of the two components are presented in Table 1 with their suggested assignments [33,37].

For the IR spectra, the atmospheric contribution was corrected whether for the ATR or Reflectance measurement mode. For the specular reflectance (SRef) analyses, the "raw" data show a large amount of bands with a derivative shape profile, mostly difficult to interpret. Since the analyzed films are homogeneous (organic films) with a good surface finishing quality and are thus rather reflective; and since the configuration of the reflectance measurements on these varnishes allow to collect preferentially the specular reflectance, the measured spectra were transformed to absorbance spectra by applying the Kramers-Kronig (KKT) algorithm (included in the software package OPUS). The relevance of this approach is confirmed by comparing the IR-SRefl spectra and the IR-ATR spectra (Fig. 1) which show bands that have same positions and also same shape. We can thus consider that the KKT applied to this kind of homogeneous organic samples can be used for "classical" spectra exploitation. However, we can notice on the corrected reflectance spectra that some large bands are miscorrected and appear negatively (around $3600 \mathrm{~cm}^{-1}$ ), but will not be considered to characterize our samples.

Fig. 1 shows also the Raman spectra of the pure materials varnish films: linseed oil and colophony. It appears that the latter present significant spectral modifications depending on the drying time of the film. Indeed, from one week to eight weeks after the application of the varnish on the glass blade, the bands are quite modified especially the band at $1650 \mathrm{~cm}^{-1}$ that decreases with time. This band is assigned to the $\mathrm{C}=\mathrm{C}$ double bonds that are very sensitive to the colophony oxidation and polymerization during the drying process [37]. This spectral modification is not observed on the IR spectra of colophony. Indeed, the $\mathrm{C}=\mathrm{C}$ bonds are hardly detected by IR spectroscopy, and no other bands seem to evolve with the drying of the colophony varnish. Indeed, the initially present $\mathrm{C}=\mathrm{C}$ double bonds on the abietic and DHA acids (Supplementary data S1), disappear from the most oxidized compound (dehydro-DHA and 7-oxo-DHA).

More generally it can be noticed, while comparing their spectra, that colophony and linseed oil present a very different

Table 1

Positions and suggested assignments of FT-Raman and IR bands for the two studied materials: colophony and linseed oil.

\begin{tabular}{|c|c|c|c|c|}
\hline \multicolumn{2}{|c|}{ Raman bands $\left(\mathrm{cm}^{-1}\right)$} & \multicolumn{2}{|c|}{ IR Bands $\left(\mathrm{cm}^{-1}\right)$} & \multirow[t]{2}{*}{ Suggested assignments } \\
\hline Colophony & Linseed oil & Colophony & Linseed oil & \\
\hline & & 3443 & 3450 & $\nu(\mathrm{OH})$ \\
\hline 3078 & & 3075 & & $\nu(\mathrm{CH})$ in $\mathrm{CH}_{2}=\mathrm{CRR}^{\prime}$ \\
\hline 2954 & & & & $\nu(\mathrm{CH})_{\text {as }}$ in $\mathrm{CH}_{3}$ \\
\hline 2929 & 2932 & 2935 & 2926 & $\nu(\mathrm{CH})_{\text {as }}$ in $\mathrm{CH}_{2}$ \\
\hline 2900 & 2910 & & & \\
\hline 2871 & & 2870 & & $\nu(\mathrm{CH})_{\mathrm{s}}$ in $\mathrm{CH}_{3} / \mathrm{CH}$ \\
\hline \multirow[t]{2}{*}{2839} & 2858 & & 2852 & $\nu(\mathrm{CH})_{\mathrm{s}}$ in $\mathrm{CH}_{2}$ \\
\hline & 1740 & 1696 & 1741 & $\nu(\mathrm{C}=\mathrm{O})$ \\
\hline 1655 & 1662 & & & $\nu(\mathrm{C}=\mathrm{C})$ \\
\hline \multicolumn{5}{|l|}{1611} \\
\hline 1470 & & 1458 & 1460 & $\delta(\mathrm{CH})_{\text {as }}$ in $\mathrm{CH}_{3} / \mathrm{CH}_{2}$ \\
\hline 1448 & 1446 & & & \\
\hline & & 1384 & 1374 & $\delta(\mathrm{CH})_{\text {as }}$ in $\mathrm{CH}_{3}$ \\
\hline 1303 & 1305 & & & $\delta(\mathrm{OH})$ \\
\hline \multirow[t]{3}{*}{1203} & & 1242 & & $\delta(\mathrm{COH})$ \\
\hline & & 1179 & 1164 & $\nu(\mathrm{CO}) ?$ \\
\hline & 1082 & & 1097 & $\nu(\mathrm{CO})$ \\
\hline \multirow[t]{2}{*}{884} & & & & $\delta(\mathrm{CH})$ in $\mathrm{CH}_{2}=\mathrm{CRR}^{\prime}$ \\
\hline & 865 & 824 & & $\delta(\mathrm{COH}) ?$ \\
\hline 742 & & 745 & & $\nu(\mathrm{CC})$ carbon skeleton \\
\hline 711 & & 714 & 727 & \\
\hline
\end{tabular}

morphology of bands. The colophony spectra show many sharp bands in the fingerprint region (1850-400 $\mathrm{cm}^{-1}$ ), but also more structured profiles than the linseed oil spectra, for example the region around $2900 \mathrm{~cm}^{-1}$, assigned to the stretching vibrations of $\mathrm{CH}$ bonds. This difference in the shape and profile of the bands allow us to consider that a spectral decomposition procedure should be efficient and enable us the development of a quantitative approach.

\section{Data treatment and quantification methodology}

\subsection{Data pre-treatment}

In order to get rid of some experimental factors that may hinder the spectral decomposition procedure, pre-treatments were necessarily done on the vibrational data.

First a polynomial baseline was subtracted (using OPUS software, Bruker) for all the spectra (pure materials and mixtures) chosing the same points in order to have a reproducible subtraction. Although the Raman spectra present a rather flat baseline, the IR spectra show very variable and very different backgrounds mostly linked to the contact with the crystal for the ATR measurements, or to the surface aspect of the analyzed films and the KKT calculation in the case of the reflectance analyses. This step allows us to get rid of the experimental and/or the mathematical conditions, and to be able to process information that are related only to the chemistry of our varnish samples.

Another experimental factor that is not easy to control is the analyzed volume, or the thickness of the sample that is probed by the different techniques. Since the thickness is not monitored during the applications, and since the prepared varnishes do not have the same viscosity, some areas present over-thicknesses. For Raman, the analyzed volume depends on many parameters: the laser wavelength, the laser spot size (the objective), the refractive index of the sample, etc. So in order to overcome this experimental parameter, the Raman spectra were all scaled to the same intensity using a band related to chemical bonds that are considered of about the same amount in the resin and the oil: the $\mathrm{CH}$ stretching massif around $2900 \mathrm{~cm}^{-1}$.

For IR-ATR, the analyzed thickness is related to the wavelength of the incident beam, and to the sample reflective index which is assumed equivalent for our two materials. Since the prepared films are about $100 \mu \mathrm{m}$, and the analyzed depth is theoretically about $3-5 \mu \mathrm{m}$, we can consider that the absorbance is probed within the same thickness of material. For the IR-SRefl, the samples have to be thick enough to avoid the signal of the glass support. Moreover, the resulting absorbance spectra (after the KKT) should show only the specular reflection of the varnish films. Considering the similar nature of our samples and their similar surface state (smooth and shiny), we can pretend that reflectance efficiency and optical index, thus the penetration depth, are about the same for all the samples. It can therefore not be necessary to normalize the IR spectra, but in order to get rid of the "analyzed thickness" parameter and to ensure reproducibility in the next steps of the data process, we chose to normalize all the IR spectra using the $\mathrm{CH}$ stretching massif around $2900 \mathrm{~cm}^{-1}$ as well.

The last step of pre-treatment consists in choosing the most interesting spectral regions to process. Two regions were picked out (see Fig. 1): the first one is related to the $\mathrm{CH}$ stretching vibrations region, called "Region 1" $\left(3180-2500 \mathrm{~cm}^{-1}\right.$ for Raman, $3180-2695 \mathrm{~cm}^{-1}$ for IR); and the second one in the fingerprint region, called "Region 2" (1830-670 $\mathrm{cm}^{-1}$ for Raman, 1900$1325 \mathrm{~cm}^{-1}$ for IR-ATR and $1900-1332 \mathrm{~cm}^{-1}$ for IR-SRefl). 


\subsection{Spectral decomposition and quantification procedure}

The aim of this study is to develop a methodology to quantify the different compounds of a mixture using vibrational spectroscopy. For this purpose, experimental varnishes were prepared with different amounts of colophony in linseed oil, and the two used materials were also applied as "pure" varnishes. In order to quantify these two materials in the mixtures using vibrational spectroscopy, a spectral decomposition tool is necessary. For this study, homemade software (PALME, D. Baron, MONARIS) was used. It considers a mixture spectrum as a linear combination of the suspected pure materials spectra [38-41]. In other words, the sum of the pure materials spectra must fit the mixture experimental spectrum. This linear combination and fitting procedure, based on a least squares method, is performed on the intensities of the spectra:

$\mathrm{MS}=\sum_{1}^{n} \alpha_{n}\left(\mathrm{PS}_{n}\right)$

where MS is the mixture spectrum, PS is the pure (material) spectrum and $\alpha$ is the weight coefficient of the PS.

It makes the hypothesis that the pure materials spectra used are representative of these materials in the mixture, in other words that the materials evolutions and possible interactions with each others have no impact on the mixtures spectra. The software needs also the definition of a baseline in order to complete the adjustment procedure. Since the spectra were already baseline corrected, it was declared as constant in order to position the origin of the spectra at zero.

After the calculation was done, PALME software provides a graphical result of the fitting, and also the contribution of each pure material spectrum to the adjustment. In our case, the relative amounts of colophony and linseed oil are given for each mixture spectrum fitting. The proportions are provided in two different coefficients (in \%): the first one corresponds to the weight coefficient $a$, and the second one to the proportion of the pure material spectrum area within the mixture spectrum total area, in other words, the area of the pure material spectrum weighted by the á coefficient.

Depending on the exploited technique, either one of the coefficients will be use. Indeed, for Raman, the proportions are described by the spectra intensities, so the weight coefficient $a$ will be used to reflect the pure materials proportions. For IR, the absorption is directly related to the bands areas, the second coefficient (area proportion) will thus be used to quantify the materials.

\subsection{GC/MS and GC: quantification approach}

In this study, the GC/MS and GC approach is intended to validate the vibrational developed procedure. Using separation methods to quantify the different components of a mixture is an established technique and can be done using different procedures [42]. As we are dealing with binary mixtures, the preferred approach on our samples consists in a relative quantification of the two components. The compounds amounts are determined with respect to each other by calculating ratios of their chromatographic peaks areas, considering that the total of the peak areas reaches $100 \%$. This method was chosen in order to have the same kind of quantification that is used for the vibrational procedure.

The first step is to select the chromatographic peaks relative to the studied compounds. Therefore GC/MS analyses of the pure materials films were done and their major bio-markers (most intense peaks) were identified thanks to their mass spectra $[36,43]$. The selected peaks are the following (see online Supplementary data S2 and S3 for more information): for colophony, the most characteristic and intense peaks are abietic acid (at 23.1 and $23.6 \mathrm{~min}$ ), dehydroabietic acid (at $25.6 \mathrm{~min}$ ), dehydro-dehydroabietic acid (at 25.5 and $27.2 \mathrm{~min}$ ) and 7-oxodehydroabietic acid (at $29.5 \mathrm{~min}$ ); for linseed oil, the picked peaks are different fatty acids in C16 or C18 (palmitic, oleic, stearic and linoleic acids at respectively 18.0, 21.3, 21.9, and $23.0 \mathrm{~min}$ ) and azelaic acid (at $10.1 \mathrm{~min}$ ), resulting from the oxidation processes during the drying and polymerization of the oil [36,43].

It is now possible to identify these bio-markers thanks to their retention time on the mixtures chromatograms. However, they might be slightly shifted because of the use of two different apparatus, but this has no consequences on the quantification approach. The chromatograms of two mixtures: 05/95 and 40/60 are presented in Supplementary data S4. It can be noticed that some peaks do not appear on the mixtures chromatograms: the abietic acid peaks at 23.1 and $23.6 \mathrm{~min}$. This is due to the fast oxidation of abietic acid during the drying of the films [12,13]. The peak at $27.2 \mathrm{~min}$ corresponding to one isomer of di-dehydroabietic acid is very weak and impossible to integrate; it will therefore not take part in the areas ratios calculation. The peaks that will be taken into account for the relative quantification procedure are reported in Supplementary data S3. The calculation of the proportions of colophony and linseed oil in the mixture is done following this formula:

$P^{1}(\%)=100 \frac{\sum_{i}^{n} A_{i}^{1}}{\sum_{i}^{n} A_{i}^{1}+\sum_{i}^{m} A_{j}^{2}}$

where $P^{1}(\%)$ is the proportion of compound \#1 in the mixture, $A_{i}{ }^{1}$ is the area of the peak " $i$ " ( $i$ value from 1 to $n$ ) of compound \#1 and $A_{j}{ }^{2}$ is the area of the peak " $j$ " ( $j$ value from 1 to $m$ ) of compound \#2.

For each mixture sample, the proportions were determined using the data of the three recorded chromatograms (three injections per sample) and a mean value then a standard deviation were also calculated. The results are presented in Table 2 and will be discussed in the following part.

\section{Results and discussion}

In this section, the results of the quantification procedure on the vibrational data, then the use of GC as a validation technique will be presented and discussed. The presented adjustment results are the ones obtained on two representative mixtures: one (05/95) with a very low amount of colophony (5\%) and the second (40/60) with a higher amount of resin (40\% of colophony). Then for each technique used, a graphical summary of the quantification results is presented for all the mixtures.

\subsection{FT-Raman quantification}

Fig. 2 presents the fitting results of the FT-Raman spectra (Regions 1 and 2) of the two presented mixtures. The mixture spectra are adjusted using the FT-Raman spectra of the two "pure" materials varnishes, colophony and linseed oil. For Region 2, which presents variations especially in the $\mathrm{C}=\mathrm{C}$ bands, two different Raman spectra of colophony were used: a first one after 1 week of drying, and a second one, more oxidized, after 8 weeks of drying. Fig. 3 shows a graphical representation of the quantitative calculation results obtained with regard to the theoretical results (weighed amounts of linseed oil and colophony).

By comparing the results, it can be noticed that colophony is not detected for the $05 / 95$ varnish by exploiting Region 1 ( $-1 \%$ for colophony and $101 \%$ of linseed oil, Fig. 3 and Table 2), but contribute to the fitting of region 2 (Fig. 2), whether with the 1 week or 8 weeks colophony films. 
Table 2

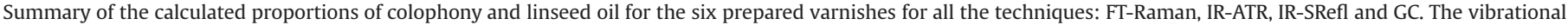
results are presented for both Region 1 and Region 2 . Some values considered as incorrect are indicated by (*), LOD=limit of detection.

\begin{tabular}{|c|c|c|c|c|}
\hline \multirow{3}{*}{$\begin{array}{l}\text { FT-Raman } \\
\text { Mixtures }\end{array}$} & \multicolumn{4}{|l|}{ Pure mat. } \\
\hline & \multicolumn{2}{|l|}{ Region 1} & \multicolumn{2}{|l|}{ Region 2} \\
\hline & Colophony (\%) & Linseed oil (\%) & Colophony (\%) & Linseed oil (\%) \\
\hline $05 / 95$ & $<$ LOD & 100 & 5 & 95 \\
\hline $10 / 90$ & 5 & 94 & 11 & 89 \\
\hline $20 / 80$ & 18 & 82 & 20 & 80 \\
\hline $30 / 70$ & 30 & 70 & 27 & 73 \\
\hline $40 / 60$ & 38 & 62 & 38 & 62 \\
\hline $50 / 50$ & 50 & 50 & 46 & 54 \\
\hline \multicolumn{5}{|l|}{ IR-ATR } \\
\hline 05/95 & 9 & 91 & 0 & 100 \\
\hline $10 / 90$ & 8 & 92 & 10 & 90 \\
\hline $20 / 80$ & 28 & 72 & 19 & 81 \\
\hline $30 / 70$ & 38 & 63 & 31 & 69 \\
\hline $40 / 60$ & 39 & 61 & 37 & 64 \\
\hline $50 / 50$ & 50 & 50 & 44 & 56 \\
\hline \multicolumn{5}{|l|}{ IR-SRefl } \\
\hline 05/95 & 10 & 90 & 1 & 99 \\
\hline $10 / 90$ & 13 & 87 & 6 & 94 \\
\hline $20 / 80$ & 18 & 82 & 17 & 83 \\
\hline $30 / 70$ & 30 & 70 & 26 & 74 \\
\hline $40 / 60$ & 36 & 65 & 35 & 65 \\
\hline $50 / 50$ & 45 & 55 & 45 & 55 \\
\hline \multicolumn{5}{|l|}{ GC } \\
\hline & Colophony (\%) & Mean colophony $(\%) \pm$ std deviation & Linseed oil (\%) & Mean linseed oil $(\%) \pm$ std deviation \\
\hline 05/95 & 3.4 & $3.2 \pm 0.2$ & 96.6 & $96.8 \pm 0.2$ \\
\hline & 3.0 & & 97.0 & \\
\hline & 3.2 & & 96.8 & \\
\hline $10 / 90$ & 8.0 & $7.9 \pm 0.6$ & 92.0 & $92.1 \pm 0.6$ \\
\hline & 7.2 & & 92.8 & \\
\hline & 8.4 & & 91.6 & \\
\hline $20 / 80$ & 17.2 & $16.9 \pm 0.5$ & 82.8 & $83.1 \pm 0.5$ \\
\hline & 17.1 & & 82.9 & \\
\hline & 16.1 & & 83.7 & \\
\hline $30 / 70$ & 26.4 & $26.2 \pm 0.2$ & 73.6 & $73.8 \pm 0.2$ \\
\hline & 26.4 & & 73.6 & \\
\hline & 26.0 & & 74.0 & \\
\hline $40 / 60$ & 35.0 & $37.3 \pm 2.0$ & 65.0 & $62.7 \pm 2.0$ \\
\hline & 38.4 & & 61.6 & \\
\hline & 38.5 & & 61.5 & \\
\hline $50 / 50$ & 44.3 & $44.9 \pm 0.9$ & 55.7 & $55.1 \pm 0.9$ \\
\hline & 45.6 & & 54.4 & \\
\hline & $32.9\left(^{*}\right)$ & & $67.1\left(^{*}\right)$ & \\
\hline
\end{tabular}

For the 40/60 varnish, both compounds have an important contribution regarding the two spectral regions (Fig. 2). However, it is notable that the adjustment of Region 2 of the 40/60 mixture is better with the "oldest" colophony varnish, especially at around $1650 \mathrm{~cm}^{-1}$. We can assume that colophony is with a higher oxidation state in the mixture varnish than in the pure colophony film.

With a deeper observation of Fig. 3 and Table 2, we can notice that low concentrations of colophony are well determined using Region 2; the red triangles are on the dotted line for the 10/90, 20/ 80 and 30/70 varnishes. On the contrary, the higher amounts of colophony are best detected using Region 1; the red circles are on the dotted line. This can be explained by the differences in the bands amounts and morphologies: Region 2 is the fingerprint region, the band positions are specific to each material, and small differences in their concentrations will easily be observed on this region. Contrary, Region 1 is the $\mathrm{CH}$ massif region, where bands are quite similar in terms of width and positions for natural organic materials, small variation in the compounds amounts will not easily be detected. Thereby, detection and quantification of small amounts are more accurate using the fingerprint region, and for higher concentrations the use of $\mathrm{CH}$ massif is convincing as well.

\subsection{IR quantification: ATR and reflectance}

For the IR analyses, the adjustment results are presented in Figs. 4 and 5 respectively for the ATR mode and specular reflectance mode. A graphical representation of the quantification results using both analytical modes are shown in Fig. 6, and the results of the calculations are presented in Table 2.

The first remark that can be set is that the results using IR-ATR and IR-SRefl are comparable or even identical in terms of spectral adjustment. However, concerning the quantification results, they are different, the IR-SRefl being slightly less accurate (Fig. 6 and Table 2).

It can also be noticed, as for the Raman results, that colophony does not contribute to the $05 / 95$ mixture spectrum adjustment, 

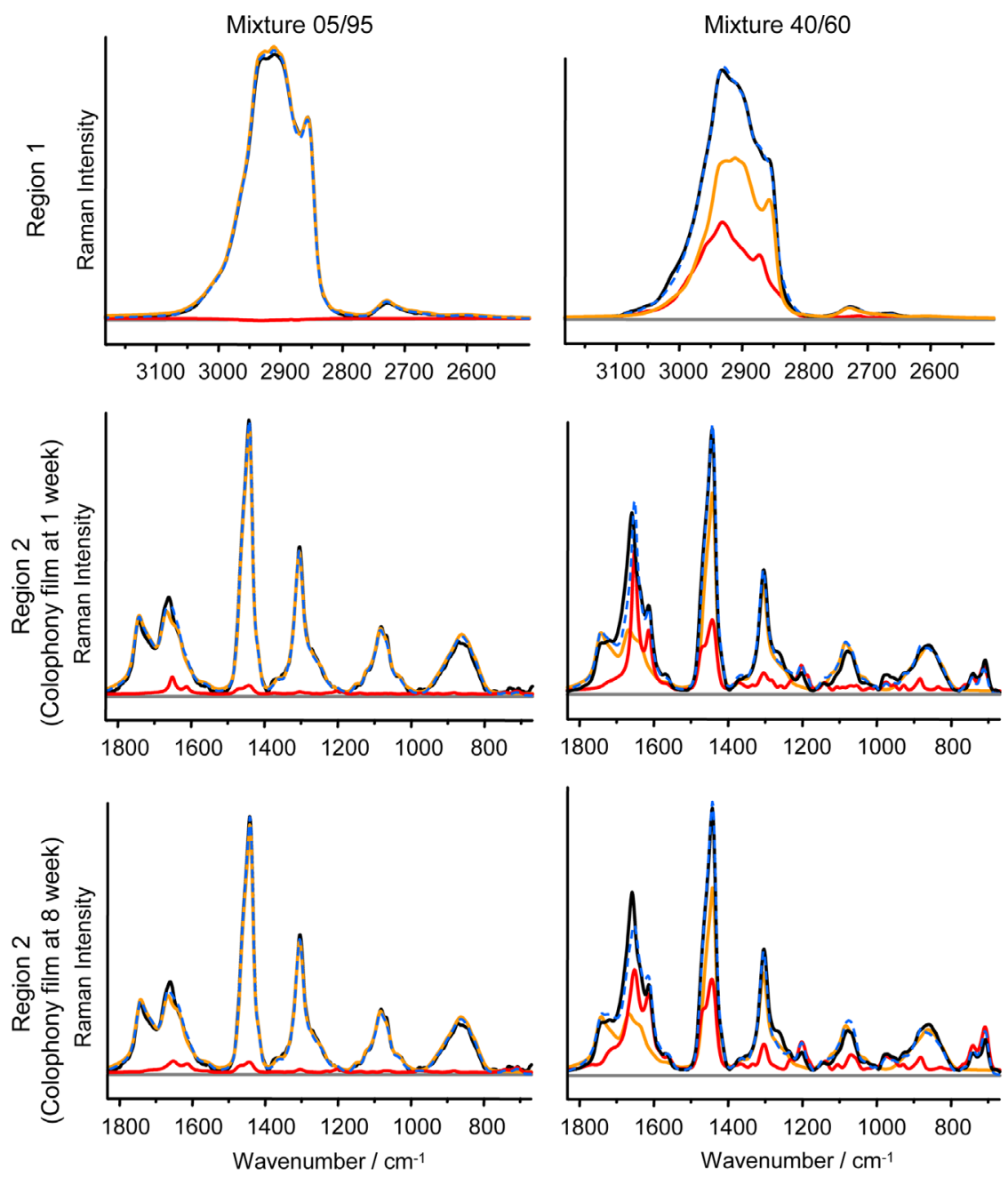

- Experimental spectrum (mixture)
---Calculated spectrum

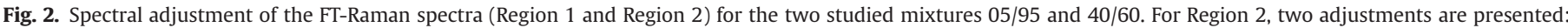
first using the 1 week dry colophony film spectrum, then the 8 weeks dry colophony film spectrum.

which means that very small amounts are not detected using these techniques. From $10 \%$ of colophony to $30 \%$, the quantification results are more satisfying using Region 2 of the spectra, whereas for the 40/60 and 50/50 varnishes, Region 1 is more specific.

\subsection{GC validation}

The chromatograms of the 05/95 and 40/60 varnishes are presented in Supplementary data S4, and the quantification results for all the prepared varnishes are displayed in Table 2. In a general way, the detected amounts are close to the expected quantities and the gap decreases with the increase of the colophony amount. The high proportions are determined with a $10 \%$ relative error, and the lowest one with a 20\% relative error. This rather important error may have different explanations: some biomarkers are absent from the mixtures chromatograms such as abietic acid and are not considered in the quantification procedure; and some others are too weak to be integrated such as the dehydro-DHA acid peaks, which distort the results.

\subsection{Pure materials' ageing: representativity of their spectra}

It was previously discussed that colophony is more oxidized in the mixture varnishes than on the pure material film. In order to support this hypothesis, a better look at the proportion measured by GC of each bio-marker in linseed oil and colophony, and according to the different varnishes, is presented in Tables 3 and 4. Concerning linseed oil (Table 3 ), we can observe that the relative amounts of fatty acids C16:0, C18:0 and C18:2 are relatively constant in all the prepared varnishes.

For oil varnishes, free radical oxidation reactions occur for the curing and polymerization of the film. When there is an important amount of linseed oil (10/90 and 05/95 varnishes), this phenomenon increases. This leads to, on one side, an important proportion of C9:0 compound (azelaic acid) that derives from this curing process and a decrease of C18:1 oleic acid that oxidized (loss of the insaturation); and on the other side, to and important amount of 7-oxo-DHA, colophony's most oxidized product in our varnishes.

When the global amount of linseed oil decreases (20/80 to 50/ 50 varnishes), the oxidation process is reduced, and colophony's first oxidation products (DHA and dehydro-DHA) are observed, as well as the C18:1 compound of linseed oil.

A previous study by van den Berg et al. [13] presented similar results and developed the definition of an oxidation index to qualify the oxidation state of colophony in several varnishes.

This was also shown on the Raman spectra of the colophony films with different time of drying (Fig. 1) especially in the fingerprint region (Region 2), around $1650 \mathrm{~cm}^{-1}$. This raises the 
question of the suitability and representativity of the colophony spectrum for the mixtures spectra adjustment: it has to be with about the same oxidation state (comparable spectral features) that what it is supposed to be in the mixture. This condition could be difficult to fulfill, especially with quite ancient samples, where degradation modifies the obtained spectra. This will call for

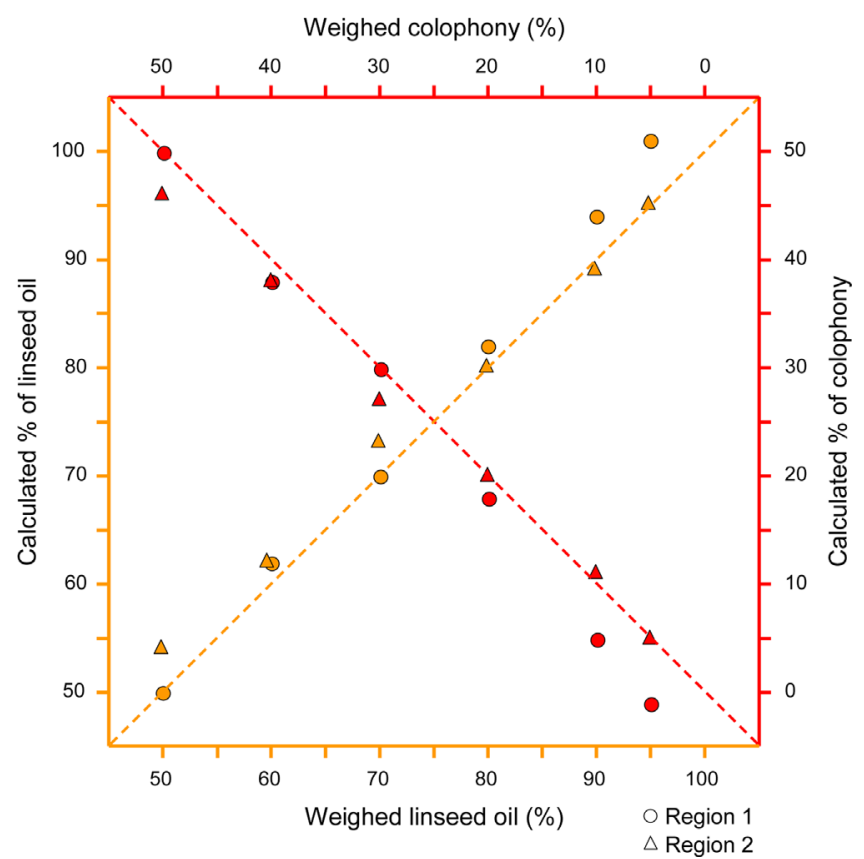

Fig. 3. Graphical representation of the quantitative calculation results obtained with regard to the theoretical results (weighed amounts of linseed oil and colophony) for FT-Raman data (Region 1: circles, Region 2: triangles). Dotted lines represent the exact correspondence between calculated and expected contents. Closer are the data to these dotted lines, more accurate is the quantification by spectral decomposition. (For interpretation of the references to color in this figure legend, the reader is referred to the web version of this article.) further detailed documentation of these substances ageing effect on their vibrational signatures. Anyway, this ageing process is not expected to excessively modify the initial molecular compositions, otherwise the information about the original recipes would be lost.

\section{Conclusion}

This study is a first step in the quantification of organic mixtures using vibrational spectroscopy. We were able to detect, identify and estimate the major compounds that can be found in a varnish. However, some advantages, but also some limits can be reported. First, we were able to evaluate a limit of detection of these compounds for Raman an IR analyses. Indeed, 5\% of colophony were not or poorly detected; but higher amounts (from $10 \%$ to $50 \%$ ) were successfully determined at least with the right order of magnitude.

Moreover, non-invasive IR analyses using specular reflectance mode were performed with relatively accurate results, which is very promising for the fully non-invasive study of varnished objects in the Cultural Heritage field. Furthermore, with the availability of portable instrument (as used in this study), going to a museum, collect and treat the data in order to identify and partially quantify the organic mixtures is a considerable step in the study of works of art. However, as discussed in this paper, the state of the analyzed surfaces (flatness, reflectivity) must provide a close to total reflectance spectra in order to process the data without any restrictions. Some ancient varnished objects, such as music instruments or furniture can be considered as very suitable for this technique and this quantitative approach.

The prepared varnishes are model samples; usually resin and oil are boiled together at high temperature and up to several hours. Thus, some chemical modifications may occur, whether for each compound (oxidation) or for the mixture (chemical interactions between the components) leading to spectral changes. So, the following points should be considered. First, if molecular modifications within the compounds (oxidation) were observed,
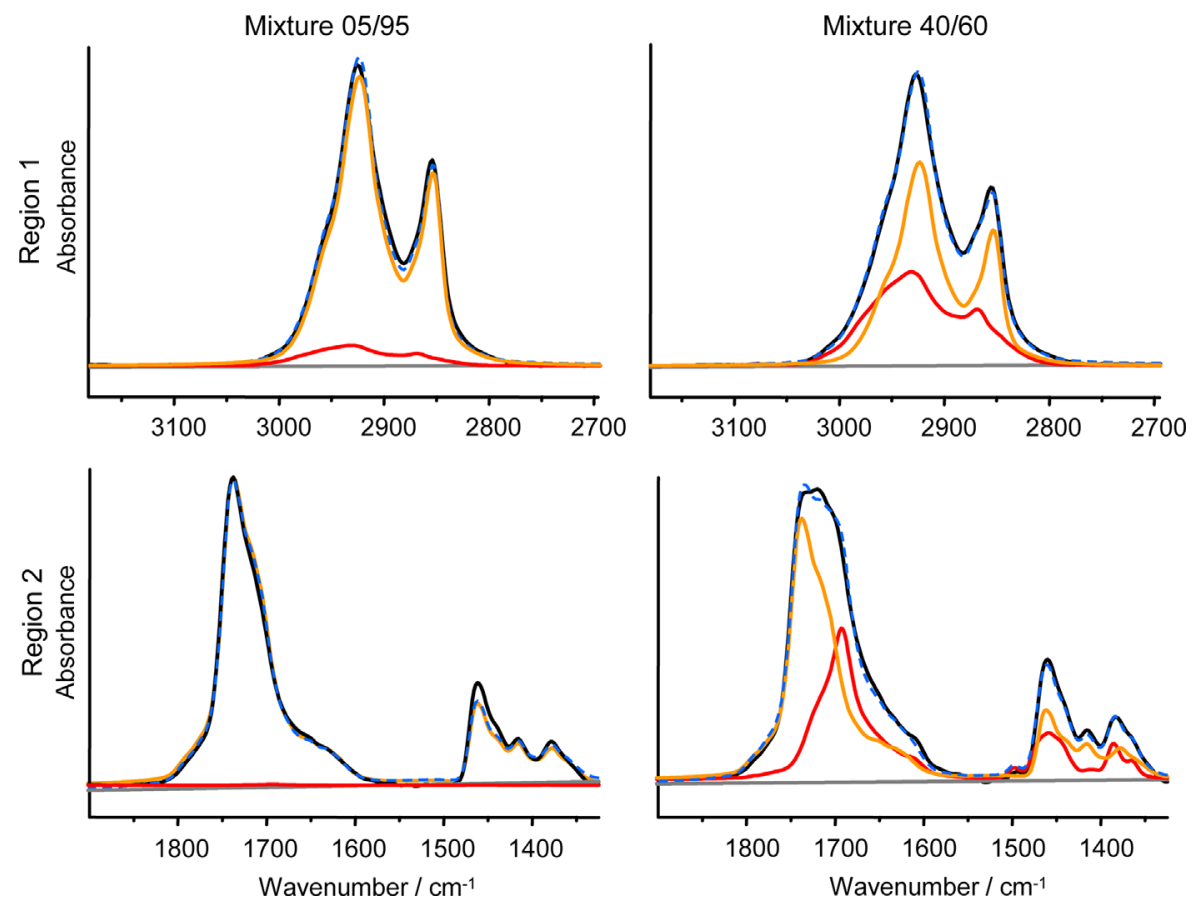

Fig. 4. Spectral adjustment of the IR-ATR spectra (Region 1 and Region 2) for the two studied mixtures 05/95 and 40/60. 

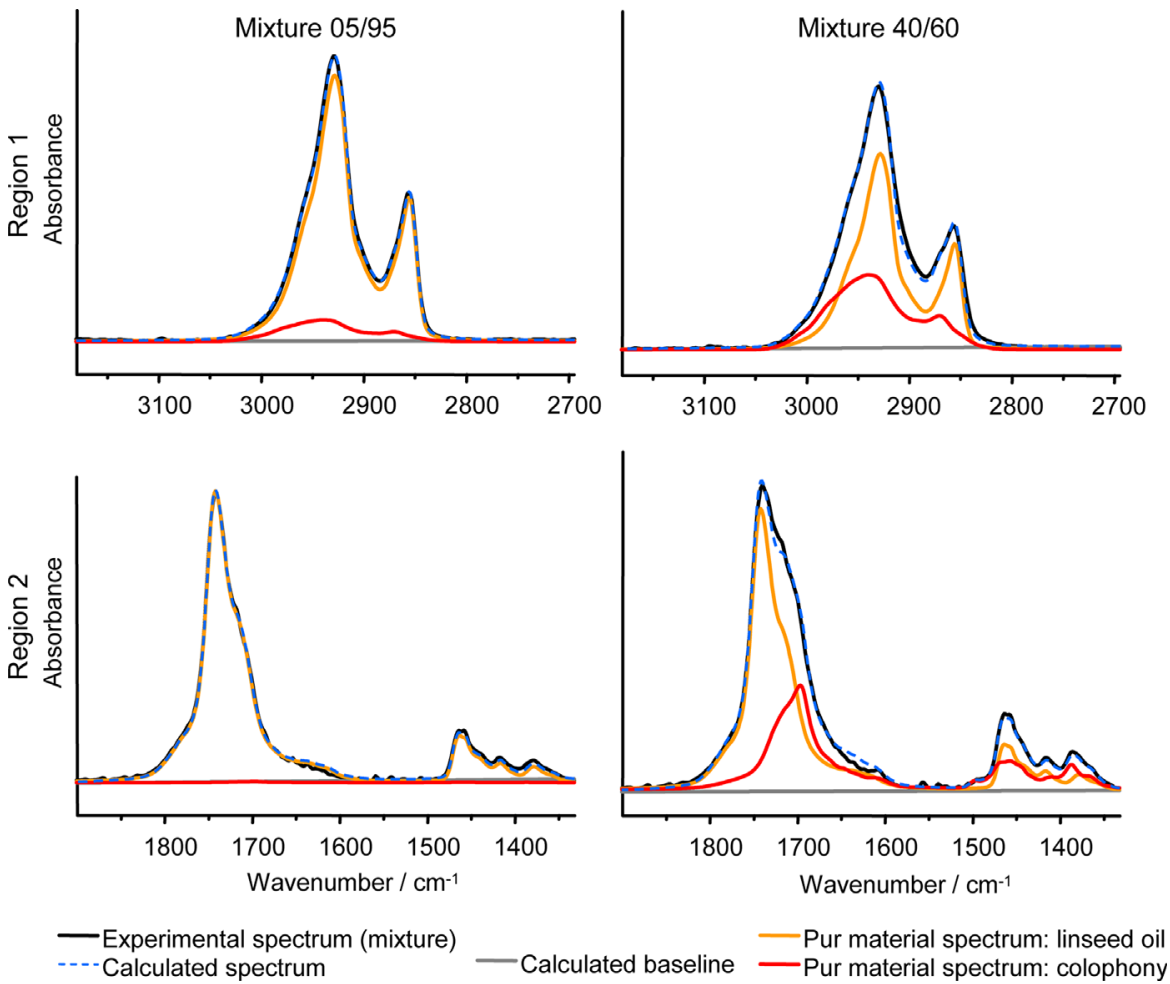

Fig. 5. Spectral adjustment of the IR-SRefl spectra (Region 1 and Region 2) for the two studied mixtures 05/95 and 40/60.

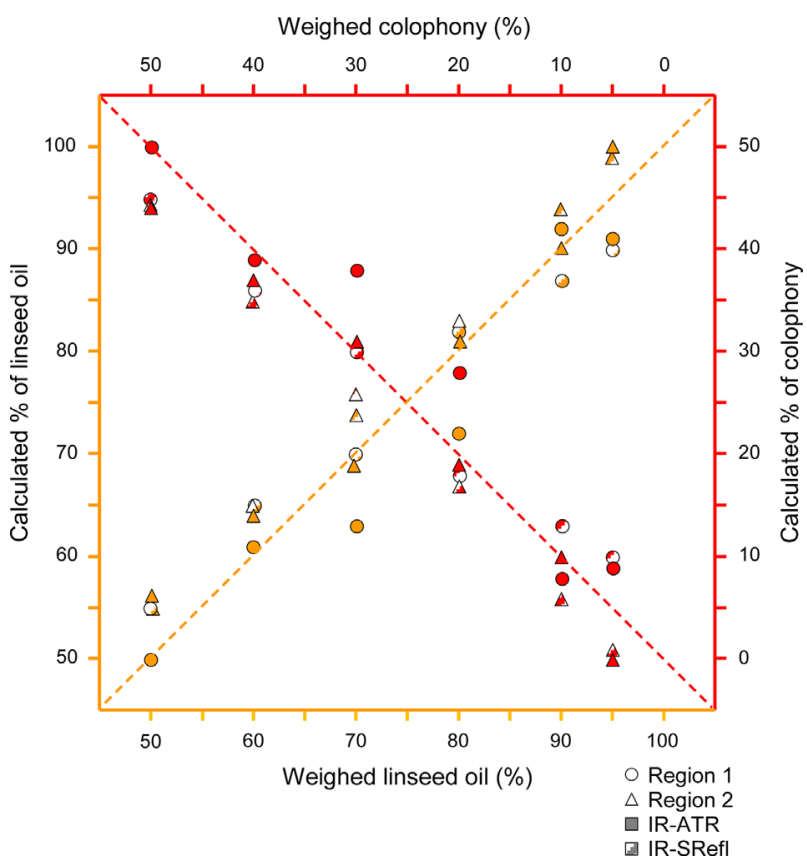

Fig. 6. Graphical representation of the quantitative calculation results obtained with regard to the theoretical results (weighed amounts of linseed oil and colophony) for IR-ATR (filled icons) and IR-SRefl (striped icons) data (Region 1: circles, Region 2: triangles). Dotted lines represent the exact correspondence between calculated and expected contents. Closer are the data to these dotted lines, more accurate is the quantification by spectral decomposition.

it could be overcome by using appropriate references. Indeed, if an ancient varnish has been boiled or the oil cooked, its spectrum should be fitted with an cooked oil spectrum as "pure" material spectrum.

Second, the approach used to estimate the varnishes composition considers the mixture spectrum as a linear combination of the
Table 3

Calculated proportions of each marker of linseed oil, for the six experimental varnishes. Some values considered as incorrect are indicated by (*).

\begin{tabular}{|c|c|c|c|c|c|}
\hline \multirow[t]{2}{*}{ Mixtures } & \multicolumn{5}{|c|}{ Linseed oil } \\
\hline & $\begin{array}{l}\text { C9:0 } \\
11.0 \text { min } \\
(\%)\end{array}$ & $\begin{array}{l}\text { C16:0 } \\
18.7 \text { min } \\
(\%)\end{array}$ & $\begin{array}{l}\text { C18:1 } \\
21.8 \mathrm{~min} \\
(\%)\end{array}$ & $\begin{array}{l}\text { C18:0 } \\
22.3 \mathrm{~min} \\
(\%)\end{array}$ & $\begin{array}{l}\text { C18:2 } \\
23.4 \text { min } \\
(\%)\end{array}$ \\
\hline $05 / 95$ & 31 & 28 & 11 & 24 & 6 \\
\hline $10 / 90$ & 30 & 28 & 14 & 23 & 6 \\
\hline $20 / 80$ & 22 & 26 & 26 & 21 & 5 \\
\hline $30 / 70$ & 32 & 31 & $7(*)$ & 25 & 5 \\
\hline $40 / 60$ & 16 & 27 & 29 & 23 & 6 \\
\hline $50 / 50$ & 19 & 28 & 26 & 22 & 5 \\
\hline
\end{tabular}

Table 4

Calculated proportions of each marker of colophony, for the six experimental varnishes. Some values considered as incorrect are indicated by (*).

\begin{tabular}{llll}
\hline Mixtures & Colophony & & \\
\cline { 2 - 4 } & $\begin{array}{lll}\text { Dehydro-DHA acid } \\
\mathbf{2 5 . 8} \text { min (\%) }\end{array}$ & $\begin{array}{l}\text { DHA acid } \\
\mathbf{2 5 . 9} \mathbf{~ m i n ~ ( \% ) ~}\end{array}$ & $\begin{array}{l}\text { Oxo-DHA acid } \\
\mathbf{2 9 . 5} \mathbf{~ m i n ~ ( \% ) ~}\end{array}$ \\
\hline $\mathbf{0 5} / \mathbf{9 5}$ & 15 & 9 & 76 \\
$\mathbf{1 0} / \mathbf{9 0}$ & 24 & 14 & 63 \\
$\mathbf{2 0} / \mathbf{8 0}$ & 24 & 21 & 55 \\
$\mathbf{3 0} / \mathbf{7 0}$ & 25 & $9\left(^{*}\right)$ & $66\left(^{*}\right)$ \\
$\mathbf{4 0 / 6 0}$ & 30 & 23 & 47 \\
$\mathbf{5 0 / 5 0}$ & 34 & 24 & 42 \\
\hline
\end{tabular}

"pure" materials spectra. This statement amounts to neglects the possible chemical reactions between the different compounds that may lead to new bonds and thereby new bands. As underlined in this work, these effects are rather circumscribed for oil/resin mixes and no new band appeared on the varnishes spectra.

Finally, some chemical influences of one compound on the other were observed. So the limitation that we faced is the 
representativity of the pure material spectrum and of its chemical state once it is mixed with other materials. One solution is to try the adjustment procedure with different spectra of a same compound with various oxidation states, and consider the one that fits the mixture spectrum as the most adequate one. The proposed approach somehow includes a control of the relevancy of the chosen references.

Moreover, in our methodology, one chosen spectral region for the study of the mixture composition is the $\mathrm{CH}$ massif around $2900 \mathrm{~cm}^{-1}$, which is, whether for Raman and IR spectra, poorly affected by the material oxidation and interactions between compounds. It is thus possible to define the mixture degradation state looking at the fingerprint region, and then adapt the choice of the pure material spectrum in order to get the best spectral adjustment.

Further works testing the proposed approach will consider more complex varnishes, with more constituents and/or of the same chemical family (presenting close vibrational spectra) in order to define its limits. Besides, forthcoming studies will use the proposed methodology for ancient varnished artifacts, non-invasively by IR reflectance, or non-destructively on microsamples using ATR-IR and Raman.

\section{Acknowledgments}

Sophie Rochut is thanked for giving us the possibility to work with GC and GC/MS at the Plateforme technologique de formation analytique et spectroscopies (Université Pierre et Marie Curie Paris 6 (UPMC), Paris (France)) and Isabelle Pellerin from the same platform for her help during the GC and GC/MS analyses.

\section{Appendix A. Supplementary materials}

Supplementary data associated with this article can be found in the online version at http://dx.doi.org/10.1016/j.talanta.2014.05. 059.

\section{References}

[1] L. Osete-Cortina, M.T. Doménech-Carbó, J. Chromatogr. A 1065 (2005) 265-278.

[2] F. Caruso, S. Orecchio, M.G. Cicero, C. Di Stefano, J. Chromatogr. A 1147 (2007) 206-212.

[3] J.-P. Echard, B. Lavédrine, J. Cult. Herit. 9 (2008) 420-429.

[4] J.-P. Echard, C. Benoit, J. Peris-Vicente, V. Malecki, J.V. Gimeno-Adelantado, S. Vaiedelich, Anal. Chim. Acta 584 (2007) 172-180.

[5] J.-P. Echard, L. Bertrand, A. von Bohlen, A.-S. Le Hô, C. Paris, L. Bellot-Gurlet B. Soulier, A. Lattuati-Derieux, S. Thao, L. Robinet, B. Lavedrine, S. Vaiedelich, Angew. Chem. Int. Ed. 49 (2010) 197-201.

[6] P. Dietemann, M.J. Edelmann, C. Meisterhans, C. Pfeiffer, S. Zumbuhl, R. Knochenmuss, R. Zenobi, Helv. Chim. Acta 83 (2000) 1766-1777.

[7] P. Dietemann, C. Higgitt, M. Kalin, M.J. Edelmann, R. Knochenmuss, R. Zenobi, J. Cult. Herit. 10 (2009) 30-40.
[8] G.A. van der Doelen, K.J. van den Berg, J.J. Boon, N. Shibayama, E.R. de la Rie, W. .L. Genuit, J. Chromatogr. A 809 (1998) 21-37.

[9] J. Mallégol, J. Lemaire, J.L. Gardette, Prog. Org. Coat. 39 (2000) 107-113.

[10] J. Mallégol, J.L. Gardette, J. Lemaire, J. Am. Oil Chem. Soc. 77 (2000) 257-263.

[11] G.A. van der Doelen, J.J. Boon, J. Photochem. Photobiol. A-Chem. 134 (2000) $45-57$.

[12] K.J. van den Berg, I. Pastorova, L.F.M. Spetter, J.J. Boon, 11th Triennal Meeting Edinburg Preprints, ICOM Comitee for Conservation, vol. 2, 1996, pp. 930-937.

[13] K.J. van den Berg, J.J. Boon, I. Pastorova, L.F.M. Spetter, J. Mass Spectrom. 35 (2000) 512-533.

[14] I. Pastorova, K.J. van den BergJ.J. BoonJ.W. Verhoeven, J. Anal. Appl. Pyrolysis 43 (1997) 41-57.

[15] M.T. Doménech Carbó, L. Osete-Cortina, J.D. Canizares, F. Bolivar-Galiano, J. Romero-Noguera, M.A. Fernandez-Vivas, I. Martin-Sanchez, Anal. Bioanal. Chem. 385 (2006) 1265-1280.

[16] J. Romero-Noguera, F.C. Bolivar-Galiano, J.M. Ramos-Lopez, M.A. FernandezVivas, I. Martin-Sanchez, Int. Biodeterior. Biodegrad. 62 (2008) 427-433.

[17] F. Rosi, A. Daveri, C. Miliani, G. Verri, P. Benedetti, F. Pique, B.G. Brunetti, A. Sgamellotti, Anal. Bioanal. Chem. 395 (2009) 2097-2106.

[18] M. Vagnini, C. Miliani, L. Cartechini, P. Rocchi, B.G. Brunetti, A. Sgamellotti, Anal. Bioanal. Chem. 395 (2009) 2107-2118.

[19] W. Vetter, M. Schreiner, e-Preserv. Sci. (2011) 10-22.

[20] P. Vitek, E.M.A. Ali, H.G.M. Edwards, J. Jehlicka, R. Cox, K. Page, Spectrochim. Acta Part A: Mol. Biomol. Spectrosc. 86 (2012) 320-327.

[21] J. Jehlicka, P. Vitek, H.G.M. Edwards, M. Hargreaves, T. Capoun, J. Raman Spectrosc. 40 (2009) 1645-1651.

[22] J. Jehlicka, A. Culka, P. Vandenabeele, H.G.M. Edwards, Spectrochim. Acta Part A: Mol. Biomol. Spectrosc. 80 (2011) 36-40.

[23] N. Navas, J. Romero-Pastor, E. Manzano, C. Cardell, J. Raman Spectrosc. 41 (2010) 1486-1493.

[24] E.S. Teodor, E.D. Teodor, M. Virgolici, M.M. Manea, G. Truica, S.C. Litescu, J. Archaeol. Sci. 37 (2010) 2386-2396.

[25] S. Prati, G. Sciutto, R. Mazzeo, C. Torri, D. Fabbri, Anal. Bioanal. Chem. 399 (2011) 3081-3091.

[26] C. Daher, L. Bellot-Gurlet, A.-S. Le Hô, C. Paris, M. Regert, Talanta 115 (2013) 540-547.

[27] N. Navas, J. Romero-Pastor, E. Manzano, C. Cardell, Anal. Chim. Acta 630 (2008) $141-149$.

[28] E. Manzano, J. García-Atero, A. Dominguez-Vidal, M.J. Ayora-Cañada, L. F. Capitán-Vallveya, N. Navas, J. Raman Spectrosc. 43 (2011) 781-786.

[29] A. Nevin, I. Osticioli, D. Demetrios Anglos, A. Burnstock, S. Cather, E. Castellucci, J. Raman Spectrosc. 39 (2008) 993-1000.

[30] A. Nevin, D. Comelli, G. Valentini, R. Cubeddu, Anal. Chem. 81 (2009) 1784-1791.

[31] Y. Shashoua, M.B.L.D. Berthelsen, O.F. Nielsen, J. Raman Spectrosc. 37 (2006) $1221-1227$

[32] C. Daher, L. Bellot-Gurlet, Anal. Methods 5 (2013) 6583-6591.

[33] M. Derrick, J. Am. Inst. Conserv. 28 (1989) 43-56.

[34] J.H. Langenheim, Plant Resins: Chemistry, Evolution, Ecology, and Ethnobotany, Timber Press, Portland, OR, USA, 2003.

[35] J.S. Mills, R. White, The Organic Chemistry of Museum Objects, 2nd ed. Butterworth-Heinemann, Oxford, UK, 1994.

[36] C. Marinach, M.-C. Papillon, C. Pepe, J. Cult. Herit. 5 (2004) 231-240.

[37] C. Daher, C. Paris, A.-S. Le Hô, L. Bellot-Gurlet, J.-P. Echard, J. Raman Spectrosc. 41 (2010) 1204-1209.

[38] S. Döpner, P. Hildebrandt, G.A. Grant Mauk, H. Lenk, W. Stempfle, Spectrochim. Acta Part A: Mol. Biomol. Spectrosc. 52 (1996) 573-584.

[39] S. Bernad, T. Soulimane, S. Lecomte, J. Raman Spectrosc. 35 (2004) 47-54.

[40] F. Salpin, F. Trivier, S. Lecomte, C. Coupry, J. Raman Spectrosc. 37 (2006) 1403-1410.

[41] J. Monnier, L. Bellot-Gurlet, D. Baron, D. Neff, I. Guillot, Ph. Dillmann, J. Raman Spectrosc. 42 (2011) 773-781.

[42] M.P. Colombini, F. Modugno, Organic mass spectrometry in art and archaeology, Wiley-Blackwell, Hoboken, New Jersey, USA, 2009, 508 pp.

[43] P. Dizabo, C. Pepe, Détection de l'acide abiétique présent dans des microprelèvements, CNRS éditions, Pigments et colorants - Ouvrage collectif: De l'Antiquité au Moyen-Âge, Paris, 1990. 